\title{
Full-Scale Wind Turbine Rotor Aerodynamics Research
}

D. A. Simms

C. P. Butterfield

Prepared for

European Wind Energy Conference

October 10-14, 1994

Thessaloniki, Greece

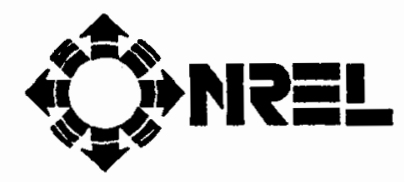

National Renewable Energy Laboratory 1617 Cole Boulevard

Golden, Colorado 80401-3393

A national laboratory of the U.S. Department of Energy Managed by Midwest Research Institute

for the U.S. Department of Energy

under contract No. DE-AC36-83CH10093

Prepared under Task No. WE418130

November 1994 


\section{NOTICE}

This report was prepared as an account of work sponsored by an agency of the United States government. Neither the United States govemment nor any agency thereof, nor any of their employees, makes any warranty, express or implied, or assumes any legal liability or responsibility for the accuracy, completeness, or usefulness of any information, apparatus, product, or process disclosed, or represents that its use would not infringe privately owned rights. Reference herein to any specific commercial product, process, or service by trade name, trademark, manufacturer, or otherwise does not necessarily constitute or imply its endorsement, recommendation, or favoring by the United States govemment or any agency thereof. The views and opinions of authors expressed herein do not necessarily state or reflect those of the United States govemment or any agency thereof.

Available to DOE and DOE contractors from:

Office of Scientific and Technical Information (OSTI)

P.O. Box 62

Oak Ridge, TN 37831

Prices available by calling (423) $576-8401$

Available to the public from:

National Technical Information Service (NTIS)

U.S. Department of Commerce

5285 Port Royal Road

Springfield, VA 22161

(703) $487-4650$ 


\title{
FULL-SCALE WIND TURBINE ROTOR AERODYNAMICS RESEARCH
}

\author{
D. A. Simms \\ C. P. Butterfield \\ National Renewable Energy Laboratory (NREL) \\ 1617 Cole Blvd. \\ Golden, CO. 80401 USA
}

\section{ABSTRACT}

The United States Department of Energy and the National Renewable Energy Laboratory (NREL) are conducting research to improve wind turbine technology at the NREL National Wind Technology Center (NWTC). One program, the Combined Experiment, has focused on making measurements needed to understand aerodynamic and structural responses of horizontal-axis wind turbines (HAWT). A new phase of this program, the Unsteady Aerodynamics Experiment, will focus on quantifying unsteady aerodynamic phenomena prevalent in stall-controlled HAWTs. Optimally twisted blades and innovative instrumentation and data acquisition systems will be used in these tests. Data can now be acquired and viewed interactively during turbine operations. This paper describes the NREL Unsteady Aerodynamics Experiment and highlights planned future research activities.

\section{BACKGROUND}

The Unsteady Aerodynamics Experiment uses a special threebladed, downwind, 10-meter-diameter wind turbine, shown in Figure 1. The rotor has $0.457-\mathrm{m}$ constant-chord NREL S809 airfoils, and operates at a constant rotation rate of 72 RPM. Blade tip pitch angle can be varied from -15 to +85 degrees. The turbine, a modified Grumman Windstream 33, has been extensively instrumented to provide accurate and detailed research data (Butterfield et. al., 1992). The measured data characterizes wind inflow, power production, tower structural modes, and aerodynamic and structural responses of the rotating blades. It has a unique set of blades, one of which is specially instrumented with 155 surface-pressure taps. The taps are oriented to provide measurements at five pressure stations located at $30 \%, 47 \%, 63 \%, 80 \%$, and $95 \%$ span. There are 28 taps at each station plus selected intermediate span locations.

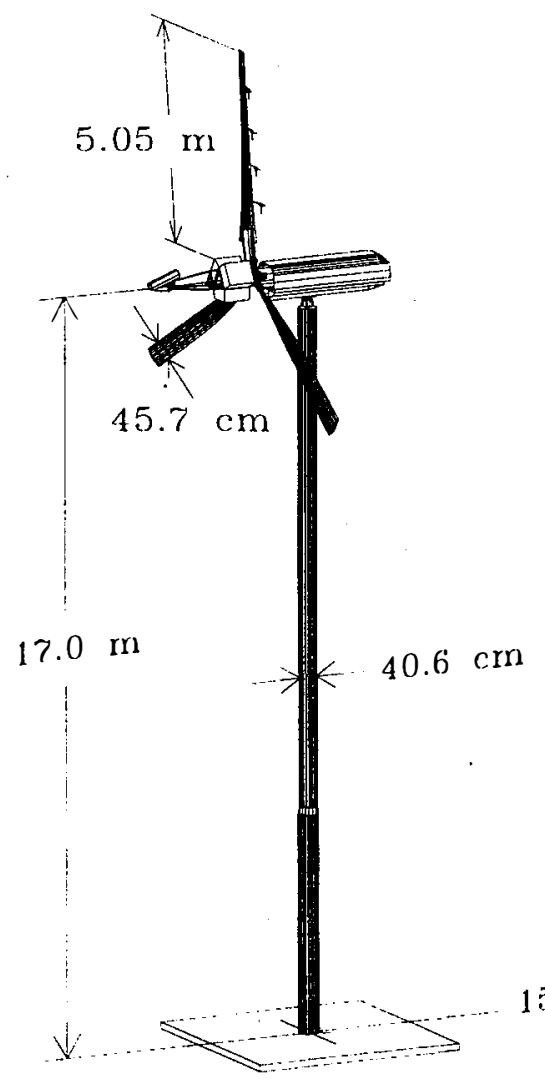

$15.0 \mathrm{~m}$

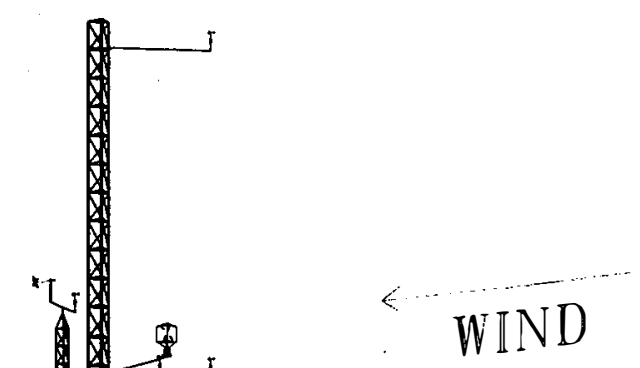

Figure 1 Unsteady aerodynamics experiment wind turbine and upwind meteorological towers 
The instrumented blade is shown in Figure 2. Surface taps are connected to five 32-channel pressure transducers located inside the blade. Pressure data from the taps enable aerodynamic lift and drag forces to be measured on the rotating airfoil.

Other channels on the instrumented blade include five stations of both dynamic pressure and local flow angle. Other rotating channels include blade flap and edge-bending moments, mainshaft bending and torsion, blade-tip acceleration, and pitch angles. Nonrotating channels include yaw position, yaw moment, tower bending, generator power, rotor RPM, and blade azimuth position. Upwind meteorological towers are also shown in Figure 1. These are instrumented to measure inflow wind velocity, wind direction, barometric pressure, and temperature. Horizontal wind shear, vertical wind shear, and boundary-layer stability are derived from the meteorological measurements.

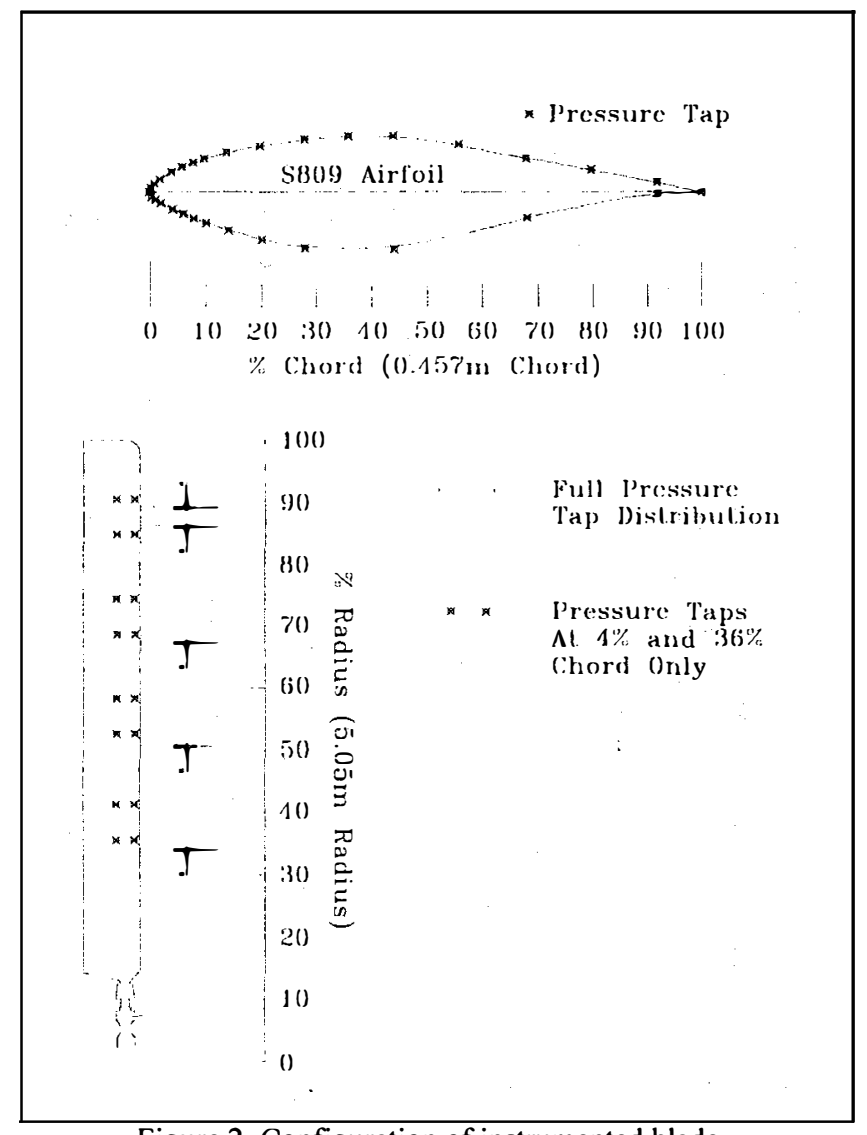

Figure 2 Configuration of instrumented blade

An important aspect of the Unsteady Aerodynamics Experiment has been to develop and refine instrumentation and data acquisition equipment needed to make required measurements. Resulting systems provide highly accurate measurements in the rugged rotating environment. Over 180 channels on the rotor are simultaneously sampled at $521 \mathrm{~Hz}$, or once per 0.83 degrees of rotation. Typical aerodynamic measurements are differential blade surface pressures in the range of $\pm 8300 \mathrm{~N} / \mathrm{m}^{2}( \pm 1.2 \mathrm{psi})$ at an estimated measurement uncertainty of $\pm 50 \mathrm{~N} / \mathrm{m}^{2}( \pm 0.007$ psi). Special equipment and computer-controlled calibration sequences are used to maintain required accuracy levels. All other nonrotating channels are sampled at the same rate, and resulting data from all 248 channels are simultaneously recorded to optical disk on a personal computer.

A special hub-mounted tripod boom can also be seen in Figure 1. Rotating data system electronics are housed in the enclosures on the inboard section of the hub boom. A video camera and lights are mounted on the outboard section. The camera focuses on the downwind suction side of the blade. It can be controlled from the ground to pan along the span and zoom on areas of interest. There is also a camera mounted at the root of the instrumented blade that looks out along the blade span. The two video cameras can record the orientation of blade surfacemounted tufts and smoke distribution to help researchers visualize the flow field. Both video camera signals are combined and synchronized with corresponding measured data values.

Earlier phases of this experiment used constant-chord, nontwisted blades. In this phase, constant-chord twisted blades are used. Blade twist distribution is shown in Figure 3. Blade twist was designed to present a constant angle of attack along the full span with the objective of producing abrupt transitions into and out of stall. Estimated spanwise angle of attack at various inflow velocities is shown in Figure 4. Results were obtained using the blade element momentum theory model called PROP (Wilson, et. al., 1976). The optimal response occurs at a tip pitch angle of -7 degrees and an inflow wind velocity of $8 \mathrm{~m} / \mathrm{s}$.

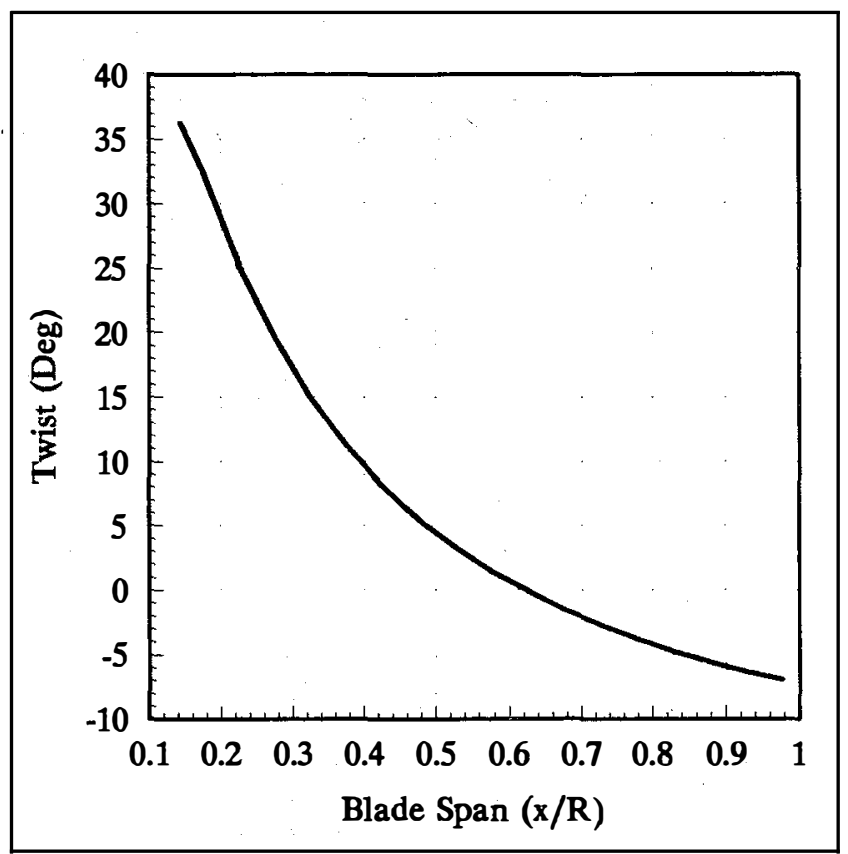

Figure 3 Blade twist distribution

Data from earlier phases of the experiment have been extensively analyzed to characterize the steady and unsteady response of the untwisted blade. During this phase, a comparison of the steady-state properties of the twisted versus non-twisted blade sets will first be pursued, on both smooth and 
rough airfoils. Next, unsteady responses of the twisted blade will be further characterized and explored.

A data measurement limitation recognized in previous phases of experimentation was due to the local flow angle flags attached to the leading edge of the instrumented blade. Blade locations of the flow angle flags are shown in Figure 2, and a detailed diagram is shown in Figure 5. Although the flags provided excellent angle of attack data during steady-state and lowfrequency transitions, their physical mass limited higher frequency responses, making it difficult to examine unsteady events. The authors suspect that the higher frequency ranges are important in estimating HAWT turbulence-induced fatigue loading. High frequency data is needed to validate dynamic stall engineering models used in analysis codes.

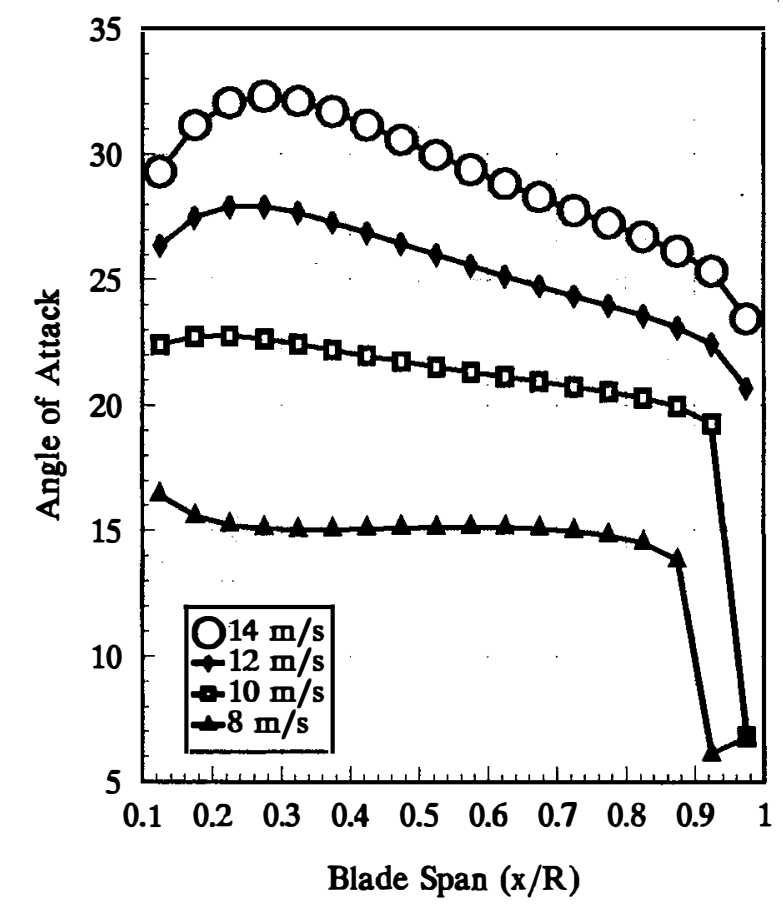

Figure 4 Estimated angle of attack distribution at -7 degrees tip pitch angle, steady state stall angle is $\mathbf{1 8}$ degrees

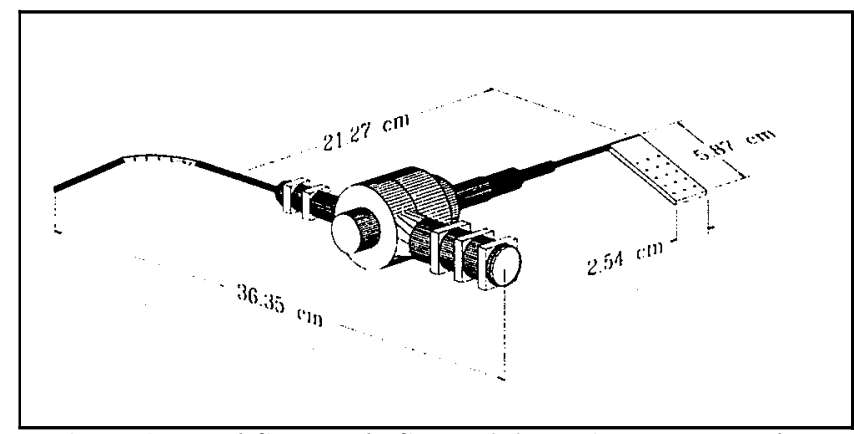

Figure 5 Local flow angle flag and dynamic pressure probe
In the current phase of experimentation, a promising new fivehole probe will be tested for use in obtaining needed highfrequency local flow angle measurements. This probe is shown in Figure 6. It will be used in place of the local flow angle flags. It can make three-dimensional angle of attack measurement to additionally estimate spanwise flow.

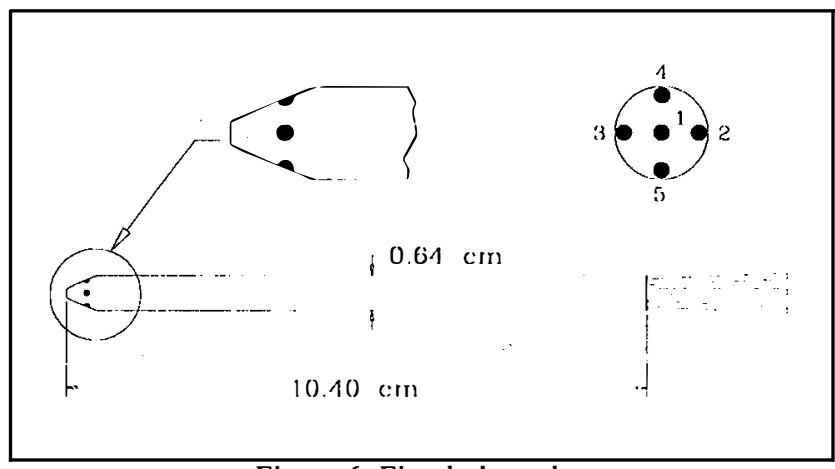

Figure 6 Five-hole probe

\section{DATA PROCESSING AND ANALYSIS}

Data sets produced in previous experiment phases have been used to develop a better understanding of steady and unsteady aerodynamic wind turbine effects (stall, dynamic inflow, yaw, tower effects) and to provide information needed to improve aerodynamic models implemented in design codes. Results have been shared with academia and the wind community. An International Energy Agency (IEA) agreement (Annex XIV "Field Rotor Aerodynamics") has been established under which information from the NREL project is being shared with other international partners. Including NREL, five organizations from four countries are collaborating to conduct similar detailed wind turbine aerodynamic test programs. This coordinated international research effort will accelerate results for a key research area and help develop a more thorough understanding of wind turbine aerodynamics.

The Unsteady Aerodynamics Experiment utilizes new data systems that have evolved to meet the needs of wind community researchers. A main objective has been to provide systems that quickly produce required results. In the past, data analyses were time consuming and expensive. Extensive computing and labor resources were needed to process the large quantities of data produced from typical events. New systems take advantage of previous analysis techniques and advanced computer technology to expedite data processing and analysis tasks. Researchers can now interpret data while the test is underway. Much effort has gone into producing software that simplifies the process of extracting and categorizing dynamic events from the large data sets. Also, the electronics system designs are flexible and can be quickly changed or reconfigured to respond to researcher requests for additional information.

\section{PREVIOUS EXPERIMENT DATA EXAMPLES}

Examples of data from a previous phase of the experiment are shown in Figures 7-10. These are typical of data sets provided to IEA Annex XIV and other researchers. 


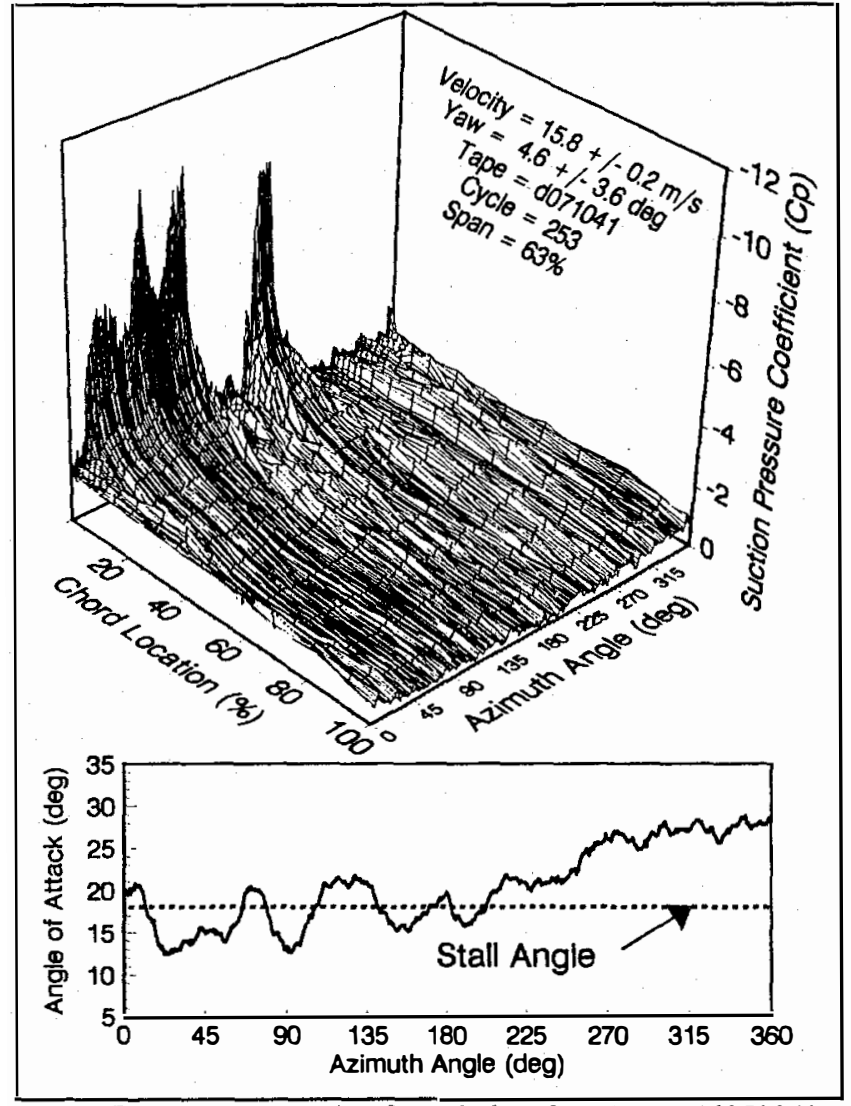

Figure 7 Pressure \& angle of attack data from event "d071041"

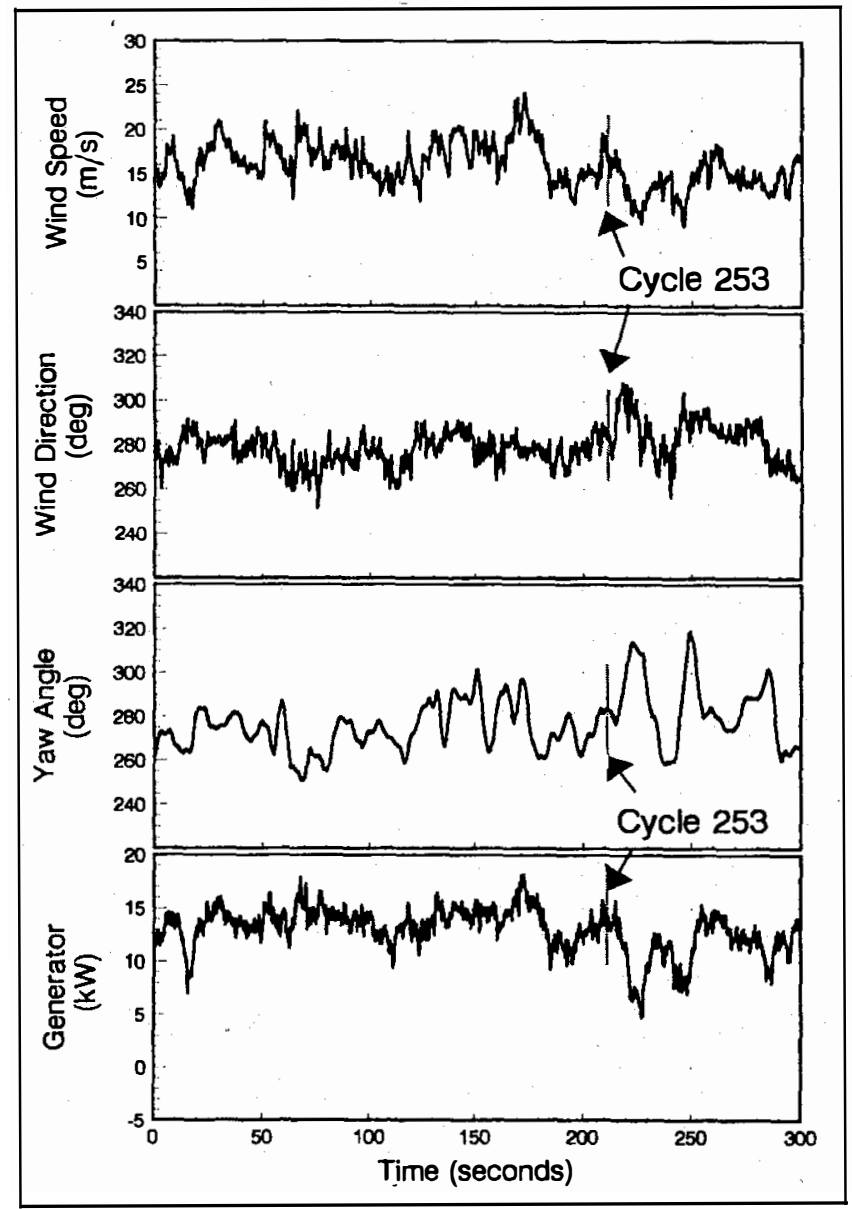

Figure 8 Operational conditions for event "d071041"

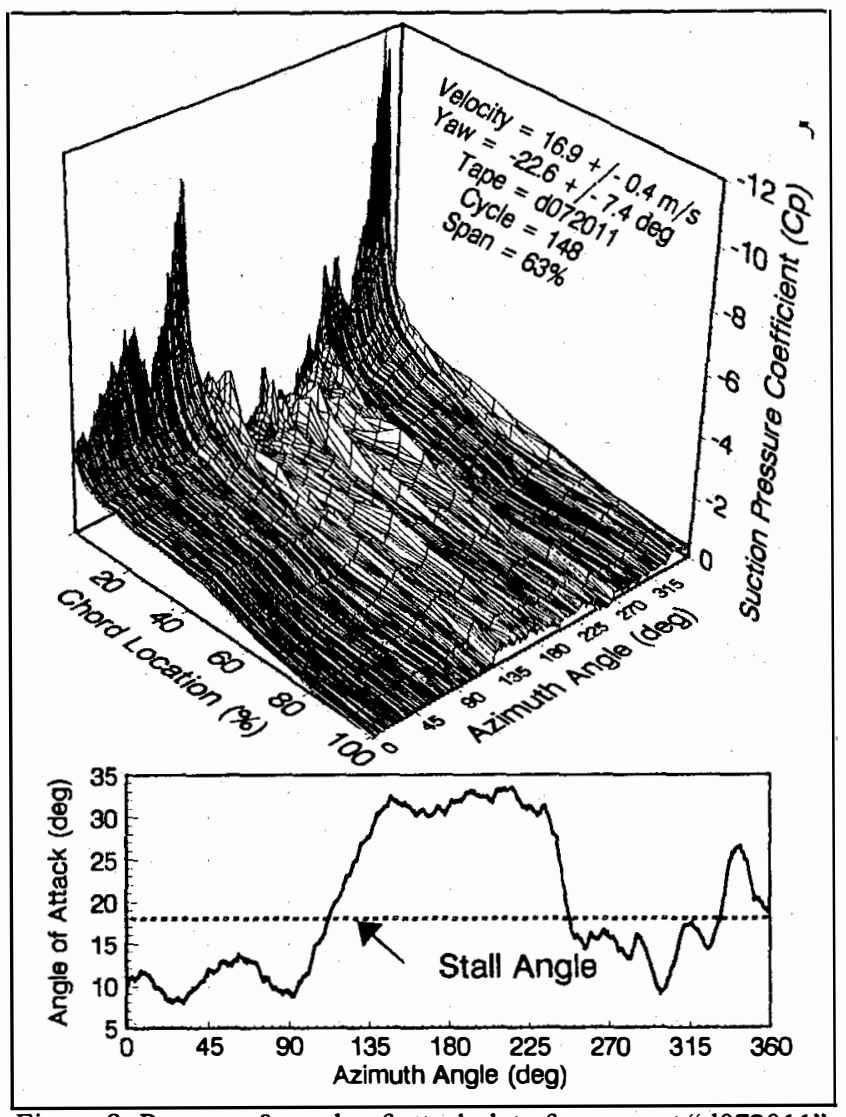

Figure 9 Pressure \& angle of attack data from event "d072011"

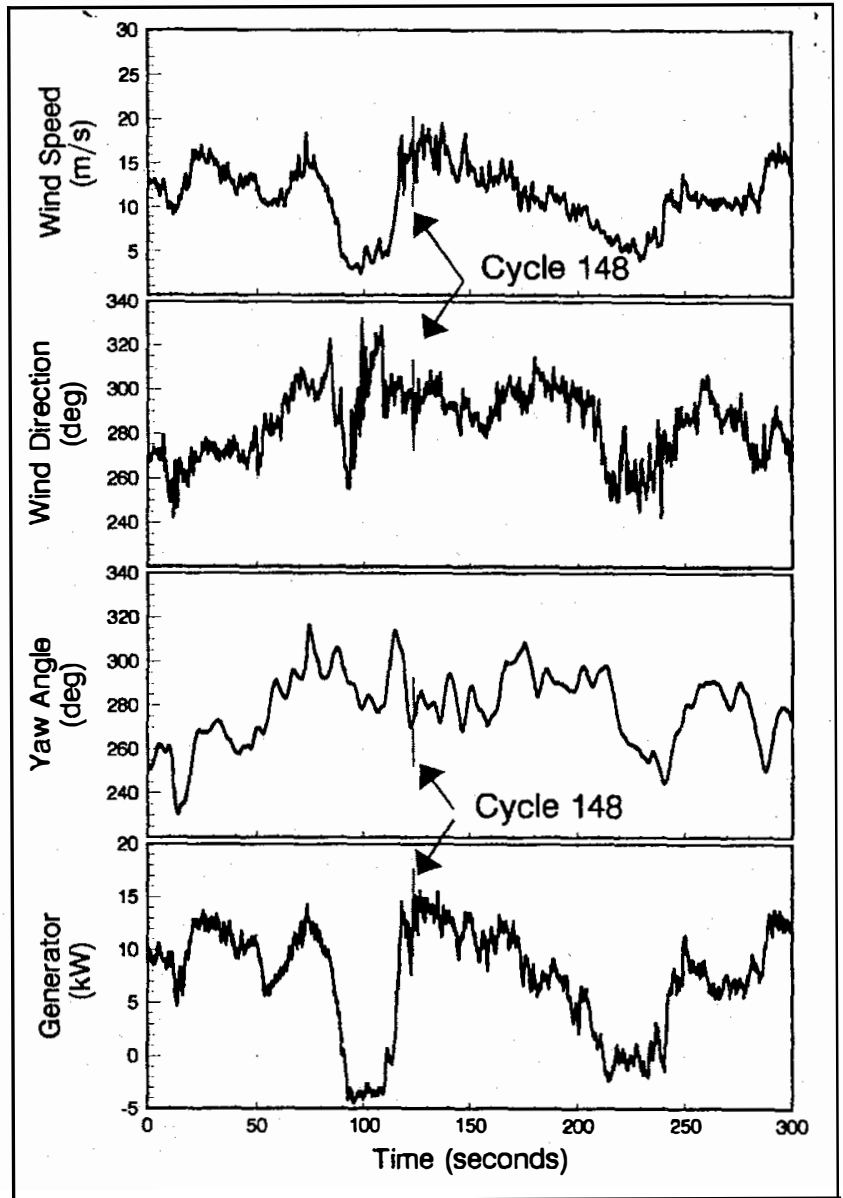

Figure 10 Operational conditions for event "d072011" 
The turbine configuration was similar to the current Unsteady Aerodynamics Experiment configuration described above, except the blades had no twist. Figure 7 is an example of four or five rapid low-amplitude airfoil transitions into and out of stall during one blade rotation cycle. The lower graph shows angle of attack at $63 \%$ span measured with the local flow angle flag. These variations represent the upper frequency response limit that the flags are capable of measuring. The upper graph shows airfoil suction pressure coefficients as a function of chord location and azimuth angle. The pressure distributions are derived from measured surface pressures and are normalized by local stagnation pressure. The largest suction pressure coefficient seen in the wind tunnel test data for this airfoil is $\mathbf{- 5}$. Note the larger suction peaks that occur as the airfoil initially sweeps down in its rotation cycle. They reach twice the wind tunnel values. This data cycle is a single 1.2 second period extracted from a 5-minute event. It is the 253rd cycle in an event labeled "d071041." Corresponding wind speed, wind direction, yaw angle, and generator power for the 5-minute event are shown in Figure 8, with the location of the cycle indicated. Note that there does not seem to be any evidence of large variations in inflow conditions that would lead one to predict the observed dynamic responses. Inflow conditions during the cycle period are relatively stable, with little variation in wind speed and yaw error. The resulting events are probably caused by turbulent inflow conditions. These conditions occur at higher frequencies or smaller characteristic lengths than the inflow anemometers can measure. As the blade passes through the tower shadow at around 180-degrees azimuth, another dynamic event occurs as the blade angle of attack quickly increases out of the tower wake.

Figures 9 and 10 show another dynamic stall example from event "d072011." In this case, a single large-amplitude transition into and out of stall is shown. It was probably caused by the 22.6-degree yaw error. Although the mean velocity in both cases is similar, the resulting aerodynamic response at $63 \%$ span is very different. These figures highlight the variability and complex nature of the rotating data, and show why high frequency data are important. It also shows the difficulty of extracting and categorizing the dynamic events in the measured data sets.

\section{PLANNED FUTURE TEST ACTIVITIES}

A summary of planned Unsteady Aerodynamic Experiment tests is shown in Table 1. The first column lists test priority and a brief test summary. The second column identifies planned measurement configuration. The standard configuration consists of all measurement channels described above. The third column identifies typical types and quantities of data to be acquired for each measurement configuration. The last column gives a brief description of analysis objectives for the given test. Standard flow angle flags will be used in the first two tests to compare with data from previous experiment phases. The fivehole probes will be used on subsequent tests. For all tests, video data of various blade-mounted tufts and smoke flows will be recorded. It is probably not feasible to conduct all tests listed in Table 1. Tests are listed to identify potential capabilities and solicit recommendations and suggestions from the user community. Test priorities and configurations will likely change in response to user comments, data requests, and updated research results.

\section{CONCLUSIONS}

NREL's Unsteady Aerodynamics Experiment will make measurements needed to understand aerodynamic and structural responses of horizontal-axis wind turbines. It will also provide information needed to improve aerodynamic models implemented in design codes. The experiment utilizes a special three-bladed, downwind, 10-meter-diameter wind turbine with constant-chord airfoils. It has been extensively instrumented to provide accurate and detailed research data. The measured data will help us characterize wind inflow, power production, tower structural modes, and aerodynamic and structural responses of the rotating blades. Many channels on the rotor are simultaneously sampled at a high rate. Blade twist was designed to present a constant angle of attack along the full span at typical wind speeds. This should produce abrupt transitions into and out of stall, and mitigate spanwise pressure gradients. Results from previous experiment phases have been shared with academia and the international wind community. We have changed the experiment configuration in response to researcher requests. A promising new five-hole probe will be tested for high-frequency local flow angle measurements. New systems take advantage of previous analysis techniques and advanced computer technology to expedite data processing and analysis tasks. An important aspect of the Unsteady Aerodynamics Experiment is to quickly produce required results so that experimental data can be quickly interpreted by researchers. Also important are versatile data systems that enable the experiment setup to be quickly changed. Future tests are planned in response to requests from university and wind industry researchers.

\section{REFERENCES}

Butterfield, C. P., Musial, W. P., Simms, D. A., "Combined Experiment Phase I Final Report," National Renewable Energy Laboratory, Golden, Colorado, NREL/TP-257-4655, October 1992.

Wilson, R. E., Lissaman, P. B., Walker S. N., "Aerodynamic Performance of Wind Turbines: Final Report", ERDA/NSF/04014-76/1, Department of Mechanical Engineering, Oregon State University, Corvallis, OR., 1976.

\section{ACKNOWLEDGMENTS}

This work was sponsored by the US Department of Energy under contract number DE-AC36-83CH10093. The authors wish to thank Derek Shipley for preparing the graphics in this report. 
TABLE 1 UNSTEADY AERODYNAMICS EXPERIMENT TESTS

\begin{tabular}{|c|c|c|c|}
\hline Test & Measurement configuration & Data Sets & Analysis Objective \\
\hline $\begin{array}{c}1 . \\
\text { Standard, No yaw }\end{array}$ & $\begin{array}{l}\text { Normal operation in standard configuration using } \\
\text { flags to measure flow angle ( } 95 \% \text { span is optional) }\end{array}$ & $\begin{array}{l}\text { Five } 10 \text {-minute free-yaw data sets distributed } \\
\text { over mean velocity from } 4 \text { to } 19 \mathrm{~m} / \mathrm{s}\end{array}$ & $\begin{array}{l}\text { Compare 3D steady unstalled and stalled aerodynamic } \\
\text { behavior of clean twisted vs. untwisted blades, and with } 2 \mathrm{D} \\
\text { wind tunnel data. }\end{array}$ \\
\hline $\begin{array}{c}2 . \\
\text { Standard, Yaw }\end{array}$ & $\begin{array}{l}\text { Same as } 1 \text {, use yaw brake and natural wind } \\
\text { direction variations to operate in extreme }\left( \pm 60^{\circ}\right) \\
\text { yaw }\end{array}$ & $\begin{array}{l}\text { Five } 10 \text {-minute extreme yaw events at medium } \\
\text { wind velocities }(10-15 \mathrm{~m} / \mathrm{s})\end{array}$ & $\begin{array}{l}\text { Compare 1P unsteady responses with theory and previous } \\
\text { clean untwisted blade pressure distributions }\end{array}$ \\
\hline $\begin{array}{c}3 . \\
\text { Five-hole } \\
\text { Probe Test }\end{array}$ & $\begin{array}{l}\text { Same as } 1 \text { except replace } 95 \% \text { flag with five-hole } \\
\text { probe; vary pitch to get data over a wide range of } \\
\text { flow angles }\end{array}$ & $\begin{array}{l}\text { Short segments of operating and high wind } \\
\text { velocity non-operating data }\end{array}$ & Compare flag and five-hole probe flow angle measurements \\
\hline $\begin{array}{c}4 . \\
\text { Probes, No-yaw }\end{array}$ & $\begin{array}{l}\text { Normal operation in standard configuration with } \\
\text { five-hole probes at each station to measure flow } \\
\text { angle }\end{array}$ & $\begin{array}{l}\text { Five 10-minute free-yaw data sets distributed } \\
\text { over mean velocity from } 4 \text { to } 19 \mathrm{~m} / \mathrm{s}\end{array}$ & $\begin{array}{l}\text { Examine selected high frequency dynamic events to provide } \\
\text { data to researchers validating Beddoes-Leishman dynamic } \\
\text { stall model }\end{array}$ \\
\hline $\begin{array}{c}5 . \\
\text { Probes, Yaw }\end{array}$ & $\begin{array}{l}\text { Same as } 4 \text {, use yaw brake and natural wind } \\
\text { direction variations to operate in extreme }\left( \pm 60^{\circ}\right) \\
\text { yaw }\end{array}$ & $\begin{array}{l}\text { Five } 10 \text {-minute extreme yaw events at medium } \\
\text { wind velocities }(10-15 \mathrm{~m} / \mathrm{s})\end{array}$ & $\begin{array}{l}\text { Examine selected high-frequency dynamic events to provide } \\
\text { data to researchers validating Beddoes-Leishman dynamic } \\
\text { stall model }\end{array}$ \\
\hline $\begin{array}{c}6 . \\
\text { No Yaw, Rough }\end{array}$ & $\begin{array}{l}\text { Same as } 4 \text {, but with standard roughness applied to } \\
\text { blade surface }\end{array}$ & $\begin{array}{l}\text { Five } 10 \text {-minute data sets distributed over mean } \\
\text { velocities from } 4 \text { to } 19 \mathrm{~m} / \mathrm{s}\end{array}$ & $\begin{array}{l}\text { Compare steady behavior of rough, twisted vs. untwisted } \\
\text { blades and wind tunnel data. }\end{array}$ \\
\hline $\begin{array}{c}7 . \\
\text { Yaw, Rough }\end{array}$ & Same as 6 & $\begin{array}{l}\text { Five 10-minute extreme yaw events at medium } \\
\text { wind velocities }(10-15 \mathrm{~m} / \mathrm{s})\end{array}$ & $\begin{array}{l}\text { Compare 1P unsteady responses with theory and previous } \\
\text { rough untwisted blade pressure distributions }\end{array}$ \\
\hline $\begin{array}{c}8 . \\
\text { Tower Wake }\end{array}$ & $\begin{array}{l}\text { Same as } 4 \text {, slow rotations }(<20 \mathrm{rpm}) \text { and use brake } \\
\text { to park blade in tower shadow }\end{array}$ & $\begin{array}{l}\text { Selected short-duration slow rotation and parked } \\
\text { blade tower wake data sets }\end{array}$ & $\begin{array}{l}\text { Characterize tower wake, data to validate tower shadow } \\
\text { models }\end{array}$ \\
\hline $\begin{array}{c}9 . \\
\text { Pitch } \\
\text { Oscillation }\end{array}$ & $\begin{array}{l}\text { Same as } 4 \text {, vary pitch angle at different rates, into } \\
\text { and out of stall, fully attached, and fully stalled }\end{array}$ & $\begin{array}{l}\text { Selected data sets in which pitch angle is } \\
\text { abruptly or sinusoidally varied }\end{array}$ & $\begin{array}{l}\text { Compare to dynamic inflow theory, data where rotor loading } \\
\text { is abruptly varied and wake adjusts over time }\end{array}$ \\
\hline $\begin{array}{c}10 . \\
\text { Selected Inflow }\end{array}$ & \begin{tabular}{|l}
$\begin{array}{l}\text { Same as } 4, \text { operate under specified inflow } \\
\text { turbulence conditions }\end{array}$ \\
\end{tabular} & \begin{tabular}{|l}
$\begin{array}{l}\text { Data sets of selected inflow turbulence } \\
\text { conditions }\end{array}$ \\
\end{tabular} & $\begin{array}{l}\text { Characterize measured turbulence, use simulated inflow } \\
\text { turbulence and compare resulting fatigue cycle counting }\end{array}$ \\
\hline $\begin{array}{c}11 . \\
\text { Tip Loss }\end{array}$ & $\begin{array}{l}\text { Same as } 4 \text {, may require operation under specified } \\
\text { conditions }\end{array}$ & Selected $95 \%$ span data & Data to validate tip loss models \\
\hline $\begin{array}{c}12 . \\
\text { Rotating Modes }\end{array}$ & $\begin{array}{l}\text { Same as } 4 \text {, operate under specified conditions or } \\
\text { excite system to create specific modal response } \\
\text { conditions }\end{array}$ & Selected rotating data sets at various rotor modes & Data to validate rotating system mode shapes and frequencies \\
\hline $\begin{array}{c}13 . \\
\text { Startup/ } \\
\text { Shutdown }\end{array}$ & Same as 4 , turbine startup and shutdown sequences & $\begin{array}{l}\text { Selected short data segments during turbine } \\
\text { startup and shutdown periods }(\sim 10 \mathrm{sec})\end{array}$ & Data to validate turbine structural dynamics models \\
\hline $\begin{array}{c}14 . \\
\text { Upwind rotor }\end{array}$ & $\begin{array}{l}\text { Same as } 4 \text {, reverse blades and rotation direction, } \\
\text { operate in locked yaw }\end{array}$ & $\begin{array}{l}\text { Five to ten } 10 \text {-minute data sets distributed over } \\
\text { wide variation in velocity and yaw }\end{array}$ & $\begin{array}{l}\text { Data with no tower shadow and nacelle blockage effects to } \\
\text { quantify tower dynamic responses and high inboard lift forces }\end{array}$ \\
\hline $\begin{array}{c}15 . \\
\text { Unbalanced }\end{array}$ & Same as 4 , operate with rotor unbalanced & Selected unbalanced rotor data & Data to validate turbine structural dynamics models \\
\hline $\begin{array}{c}16 . \\
\text { Tower Shroud }\end{array}$ & $\begin{array}{l}\text { Same as } 4 \text { and 5, operate with airfoil-shaped tower } \\
\text { shroud which moves with nacelle }\end{array}$ & $\begin{array}{l}\text { Short segments, operating and high-wind non- } \\
\text { operating data over wide range of yaw }\end{array}$ & $\begin{array}{l}\text { Data to evaluate aerodynamically shaped tower effects on } \\
\text { blade interaction }\end{array}$ \\
\hline
\end{tabular}

